\title{
PKM Perencanaan Desa Wisata Bonjeruk, Lombok Tengah
}

Muhammar Khamdevi

e-mail:m.khamdevi@gmail.com

Program Studi Arsitektur Universitas Matana

\section{Abstrak}

Desa Bonjeruk di Lombok Tengah berdiri pada tahun 1800-an ini sekilas memiliki banyak potensi dan peluang bisnis pariwisata, baik dari segi sejarah, budaya, pertanian, dan kuliner. Desa Wisata Bonjeruk sendiri ditetapkan oleh pemerintah daerah pada tahun 2019. Karena analisis dan perencanaan yang belum optimal, desa wisata ini memerlukan perencanaan yang perlu diperbarui, agar tercipta wisata yang berkelanjutan dan berbasis masyarakat. Oleh karena itu kegiatan ini sangat diperlukan untuk menghasilkan analisis dan perencanaan Desa Wisata Bonjeruk yang lebih kongkrit. Bagaimanakah perencanaan dan konsep Desa Bonjeruk yang sesuai? Kegiatan ini dilaksanakan antara Program Studi Arsitektur Universitas Matana dan Pokdarwis Bonjeruk untuk mendapatkan kolaborasi yang berbasis masyarakat. Disepakati masterplan yang disesuaikan dengan spririt of place desa.

Kata kunci: desa wisata, spirit of place, berbasis masyarakat, wisata berkelanjutan, pengabdian kepada masyarakat

\section{Abstract}

Bonjeruk Village in Central Lombok was established in the 1800s, at a glance, it has a lot of tourism business potential and opportunities, both in terms of history, culture, agriculture and culinary. The tourism village of Bonjeruk itself was established by the local government in 2019. Because the analysis and planning were not yet optimal, this tourism village needed planning that needed to be updated, in order to create sustainable and community-based tourism. Therefore, this activity is very necessary to produce a more concrete analysis and planning of Bonjeruk Tourism Village. What is the appropriate planning and concept for Desa Bonjeruk? This activity was carried out between the Architecture Study Program of Matana University and Pokdarwis Bonjeruk to get community-based collaboration. It was agreed that the master plan should be adjusted to the village spirit of place.

Keywords: tourism village, spirit of place, community based, sustainable tourism, community service 


\section{Pendahuluan}

Desa Bonjeruk terdiri dari 14 dusun. Warganya sangat homogen yang bersuku Sasak. Desa ini berdiri tahun 1800 -an, dan sempat menjadi adalah pusat pemerintahan tingkat Distrik Jonggat pada jaman Kolonial Belanda. Desa ini sangat kental dengan suasana pedesaan yang memiliki ladang basah dan ladang kering, seperti sawah padi, kebun sayur-mayur, ladang kopi, dan lain-lain. Jarak Mataram - Bonjeruk sekitar 20 kilometer ke arah tenggara atau memerlukan waktu 45 menit. Keliling di Desa Wisata Bonjeruk ini memerlukan waktu 2,5 jam dengan berjalan kaki (Khafid, 2019).
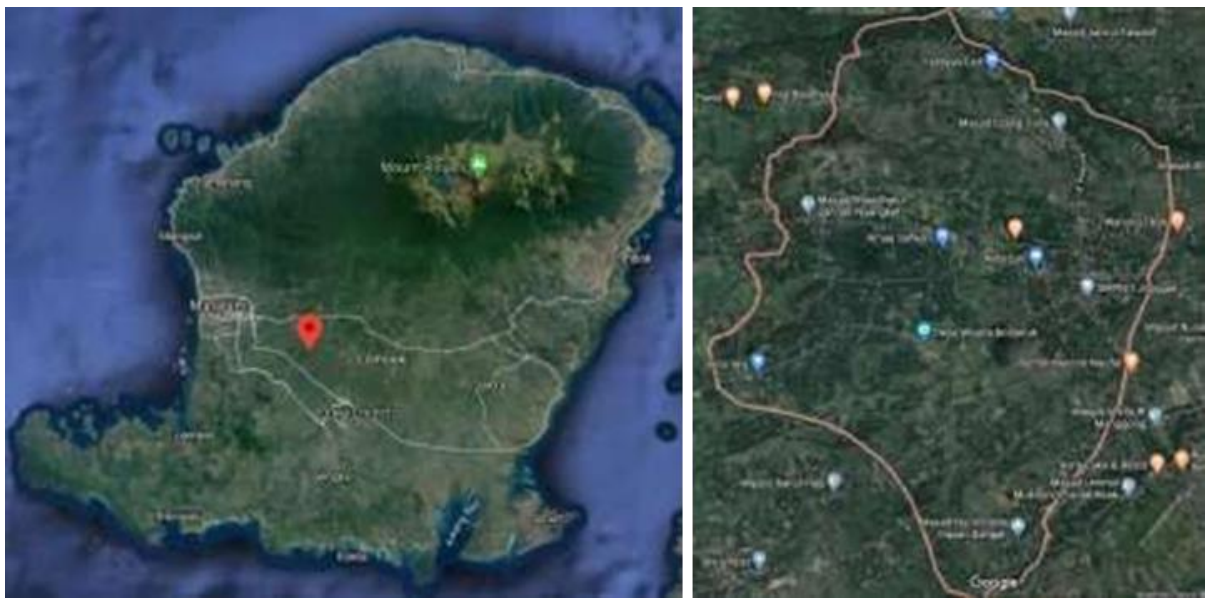

Gambar 1. Lokasi PKM

Nama desa ini didapatkan dari pada saat beberapa orang utusan Kerajaan Pujut, yang pada saat itu sedang mengalami kekeringan, menemukan sumber air di dekat pohon jeruk yang kemudian sumber air tersebut dijadikan bowon atau sumur, maka disebut Bonjeruk (Anjani, 2018).

Dalam artikelnya yang berjudul "Strategi Komunikasi Politik Kekuasaan Dalam Menjaga Eksistensi Keluarga Kerajaan di Desa Bonjeruk Kecamatan Jonggat, Lombok Tengah", Anjani (2018) menuliskan bahwa kerajaan Pujut mengutus putra mereka untuk membangun kerajaan baru di Bonjeruk, yaitu Kerajaan Datu Jonggat. Pada saat itu, Datu (Raja) dan Dinde (Ratu) Jonggat melahirkan banyak generasi dan terus melestarikan kebudayaan nenek moyang hingga sekarang, para keturunan dari Datu Jonggat inilah yang dianggap merupakan keluarga kerajaan dan dihormati oleh warga desa Bonjeruk. Para keluarga kerajaan di Lombok biasa diberikan nama Lalu bagi laki-laki, sedangkan nama Lale atau Baiq bagi wanita.

Berdasarkan sistem kasta masyarakat adat Sasak, Datu dan Dinde berada pada kasta tertinggi, sedangkan Datu dan Dinde terakhir tidak menikah dan tidak menghasilkan keturunan asli dari pernikahan Datu Dinde, yang dapat menjadi Datu atau Dinde berikutnya. Maka dari itu, sekarang kasta tertinggi menjadi Lalu dan Lale atau Baiq (Anjani, 2018). 
Pada website Pokdarwis Bonjeruk Permai, dikatakan bahwa Desa Bonjeruk terbentuk menjadi sebuah desa pada tahun 1886 setelah pernah menjadi pusat pemerintahan yakni kedatuan jonggat, Datu yang terkenal pada masa itu ialah Raden Nune Umas. Pada masa kependudukan Belanda, peranan kedatuan Jonggat dibawah kepemimpinan Raden Nune Umas sangatlah penting, karena Raden Nune Umas bersama tokoh-tokoh sasak lainnya mampu mengatur strategi untuk melepaskan diri dari Tirani Kerajaan Bali di lombok dan mendorong pemerintah Belanda untuk membantu masyarakat Suku Sasak membangun infrastruktur irigasi, perkantoran, sekolah-sekolah untuk kepentingan masyarakat itu sendiri. Sehingga karena jasanya, Beliau diangkat sebagai kepala Distrik pertama di wilayah Lombok Tengah. Kedistrikan Jonggat terakhir dipimpin oleh Lalu Srinate yang kemudian menjadi Bupati pertama di Kabupaten Lombok Tengah. Peninggalan bersejarahnya antara lain: Masjid Raden Nune Umas, Makam Bersejarah, dan sumur-sumur tua.

Hubungan Datu Jonggat, Kepala Distrik Jonggat dan Pemerintah Belanda pada saat itu sangatlah erat, sehingga banyak bangunan-bangunan yang dibuat pada masa itu di Desa Bonjeruk antara lain, Kantor Distrik Jonggat (Gedeng Beleq) pada 1933, Pasar Tenten Bonjeruk pada Tahun 1929, Saluran Irigasi pada 1930, Sekolah Rakyat (SR) pada Tahun 1949 dan Saluran Irigasi terbesar yakni Jurang Sate' (Abangan) juga dibuat atas usulan Kedistrikan Jonggat.

Sejak akhir 2019, desa ini ditetapkan oleh pemerintah daerah NTB sebagai salah satu Desa Wisata di Pulau Lombok dengan fokus pada segmen Agrowisata (NTBProv.go.id, 2019). Walau begitu desa ini memiliki potensi tidak hanya sekedar itu, namun juga sejarah, budaya, pertanian, alam, dan lain-lain yang belum tereksplor dengan baik. Selain itu, Pokdarwis Bonjeruk sudah membentuk kelompok belajar Bahasa Inggris yang diajar oleh relawan-relawan asing untuk mengamunisi warganya dengan kemampuan bahasa internasional.

Pemetaan dan perencanaan Desa Wisata yang belum matang, diperlukan konsultasi dan arahan secara keilmuan arsitektur. Oleh karena itu pemetaan dan perencanaan Desa Wisata Bonjeruk yang lebih kongkrit dan berbasis masyarakat dengan kolaburasi bersama warga Bonjeruk. Sehingga dihasilkan perencanaan desa wisata yang lebih khas, tidak mainstream hanya fokus pada "leisure and pleasure" tapi lebih ke edukasi dan "experience", tidak merusak alam, tidak mengganggu keseharian warga, tidak merusak budaya lokal dan cara berpikir warga lokal, tdan menciptakan wisata yang menjadi penghasilan sampingan warga Desa Bonjeruk.

\section{Metode Pelaksanaan}

Pendekatan metode yang digunakan adalah secara kualitatif. Sasaran peserta kegiatan ini adalah Pokdarwis Bonjeruk secara khusus dan warga Desa Bonjeruk secara umum. Kegiatan dilaksanakan di Desa Bonjeruk dan secara berkala, yang waktunya akan ditentukan ketika dilakukan analisis dan evaluasi awal. Tahapan pelaksanaan sebagai berikut:

1. Analisis Data Lapangan

2. Konsep Pemetaan dan Perencanaan 
3. Presentasi Hasil

4. Evaluasi Akhir

Dikarenakan kegiatan ini terjadi di saat Pandemi COVID-19, maka data primer didapatkan dari data lapangan yang dilakukan oleh pihak Pokdarwis Bonjeruk yang dipandu dan didampingi secara daring oleh pihak Universitas Matana. Data tersebut lalu dielaborasi bersama antara keduanya melalu Focus Discussion Group (FGD). Selain itu pihak Universitas Matana juga mengumpulkan data-data sekunder ilmiah yang tersedia secara daring di internet.

Lalu data-data yang sudah terkumpul dianalisis dengan pendekatan analisis Spirit of Place (Garnham, 1985), yakni:

1. Sistem Alamiah

2. Sistem Budaya

3. Sistem Visual

\section{Hasil dan Pembahasan}

\section{Sistem Alam}

Pada peta permukaan air di Desa Bonjeruk dapat dilihat bahwa terdapat beberapa aliran air yang letak serta kedalamannya berbeda. Sungai pada desa ini memiliki lebar yang cukup luas dan kedalaman yang dalam yang terdapat di utara desa bonjeruk, sedangkan beberapa didalam desa bonjeruk merupakan aliran saluran irigasi. Ketinggian sungai kira-kira, 10-15 permukaan tanah ke sungai. Ada yang landai dan curam 50-70 derajat.

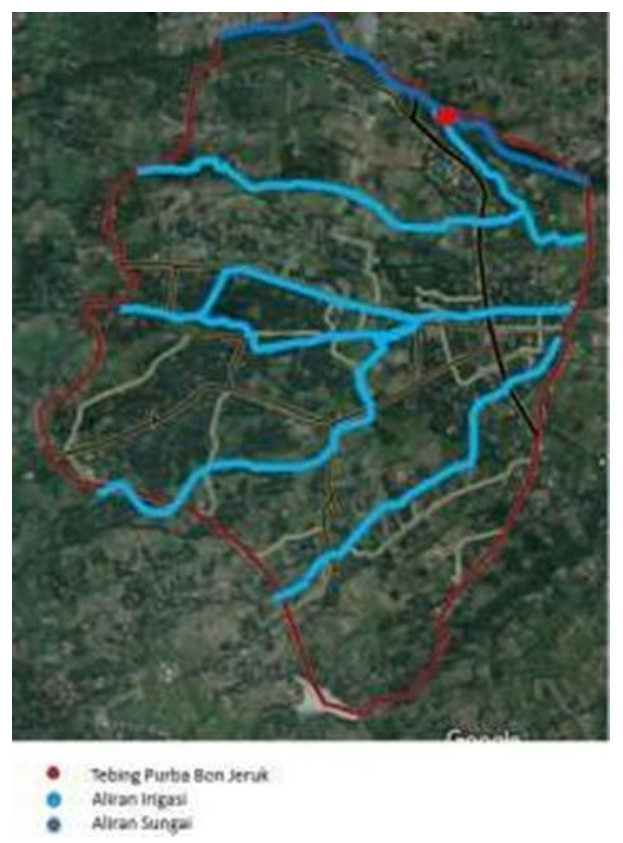

Gambar 2. Permukaan Air

Area kontur menjadi semakin tinggi ke arah utara atau Gunung Rinjani, namun jika di kategorikan pada kontur tanah, Desa Bonjeruk didominasi oleh tanah yang landai. KOntur tercuram terdapat pada tebing sungai di bagian utara desa (tebing purba). 


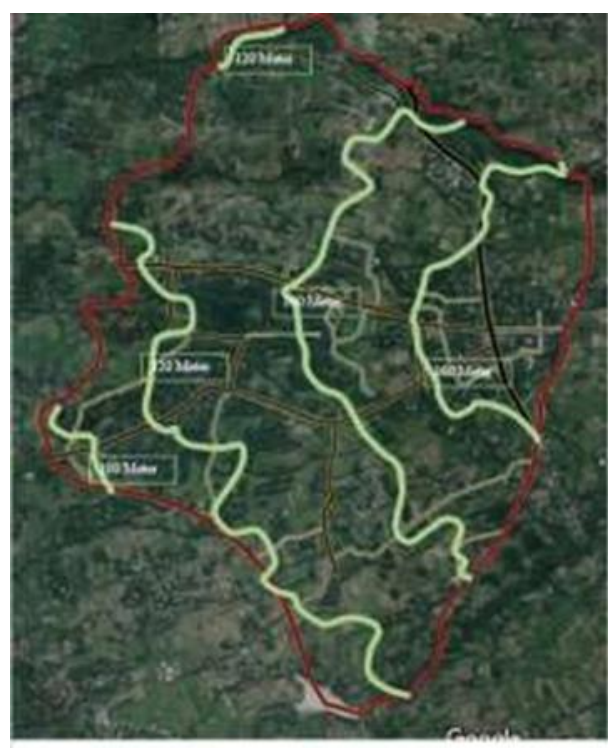

Kontur

- Tetong Purta Bon lervit

Gambar 3. Topografi

Jumlah kolom utamanya ada dua belas buah (sakarolas). Pada dinding sebelah kanan dan kiri sasoro terdapat jendela melengkung seperti kubah tanpa daun jendela. Namun sekarang jendela ini di beberapa rumah sudah ditutup dan diberi rooster oleh pemilik rumah karena untuk menghindari debu kendaraan dari jalan. Jendela berkarakter arab-islam ini sangat umum kita temukan pada rumah-rumah tradisional di Lengkong Kyai (Khamdevi, 2013), rumah kongsi Tionghoa di Banten Lama, rumah indis kolonial di Pekojan-Serang, dan rumah-rumah tradisional betawi yang sering disebut melompang. Selain itu pada kamar-kamar tidur, dan ruang tengah terdapat cerukan berbentuk segitiga agak melengkung pada dinding yang disebut lembedang (tembok berlubang), yang berfungsi sebagai tempat lampu minyak atau menyimpan Al-Qur'an.
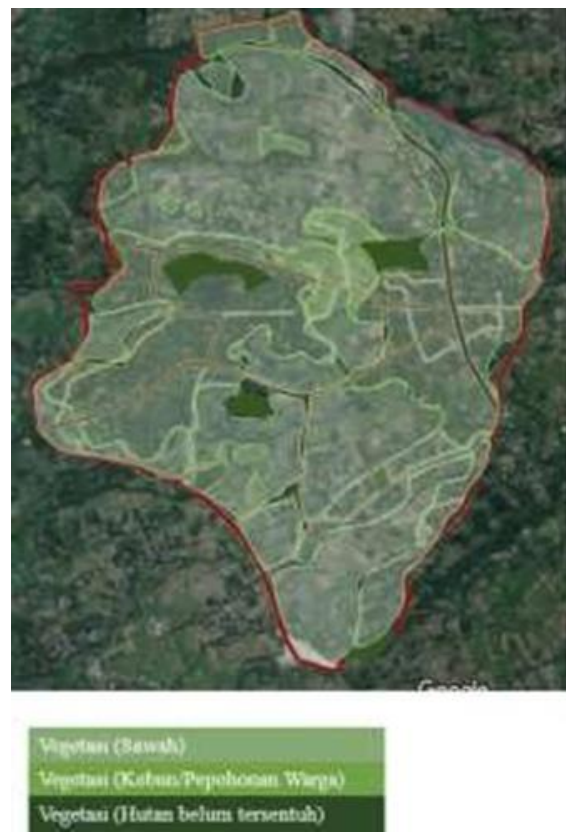

Gambar 4. Vegetasi

20 persen merupakan hutan yang belum diusik 80 persen pohon selama 50 tahun ditanam 130 | Volume 4 Nomor 2 Februari 2021 
berupa pohon oleh warga. Vegetasi lebih banyak ditemukan mengelilingin permukiman warga, dan juga sepanjang jalan antar dusun.

\section{Sistem Budaya}

Guna Lahan di wilayah Desa Bonjeruk masih didominasi oleh lahan pertanian dan perkebunan. Selain itu terdapat pula guna hunian dan komersil yang berkumpul pada jalan-jaln utama. Fasilitas desa lumayan tersedia.

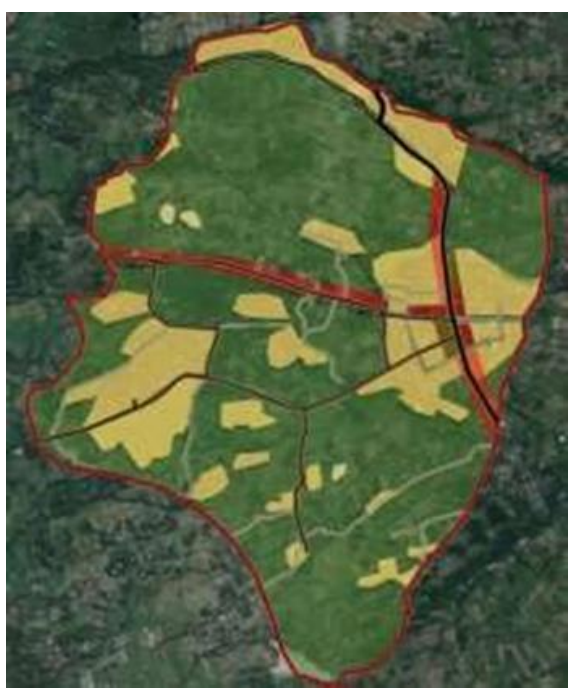

Gambar 5. Guna Lahan

Kepemilikan tanah didominasi oleh kepemilikan pribadi warga setempat, seperti lahan hunian, lahan pertanian, dan lahan perkebunan. Sedangkan lahan fasilitas desa, hutan desa, dan sungai-sungai desa adalah milik pemerintah desa. Selain itu ada beberapa lahan adalah milik adat atau kepemilikan khusus pimpinan adat, seperti makam bersejarah.

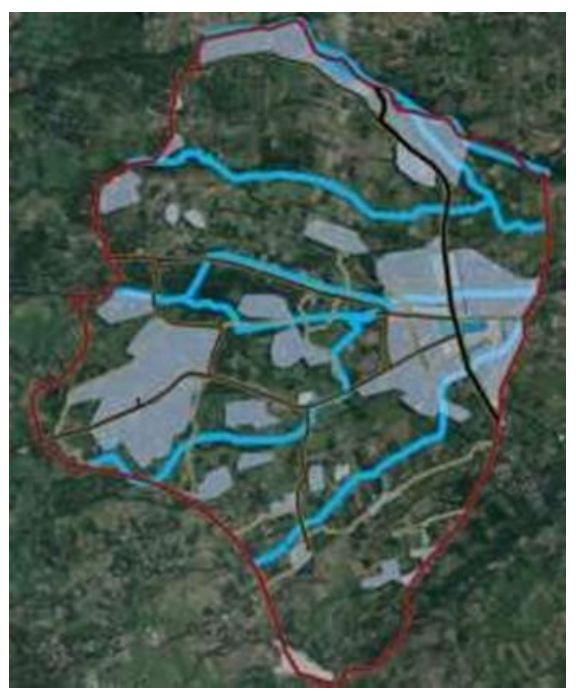

Gambar 6. Kepemilikan Tanah

Beberapa objek bersejarah terdapat di desa ini dan kebanyakan berada pada fase kolonial Belanda. Objek-objek itu antara lain Masjid Raden Nune Umas, Gedang Beleq, Pasar Lama Bonjeruk, Saluran Irigasi dan Sumur-sumur tua. Selain itu ada beberapa objek makam-makam bangsawan dan ulama di desa ini, 
PKM Perencanaan Desa Wisata Bonjeruk, Lombok Tengah

seperti Makam Datu Jonggat, Makan Kepala Distrik Van Jonggat.

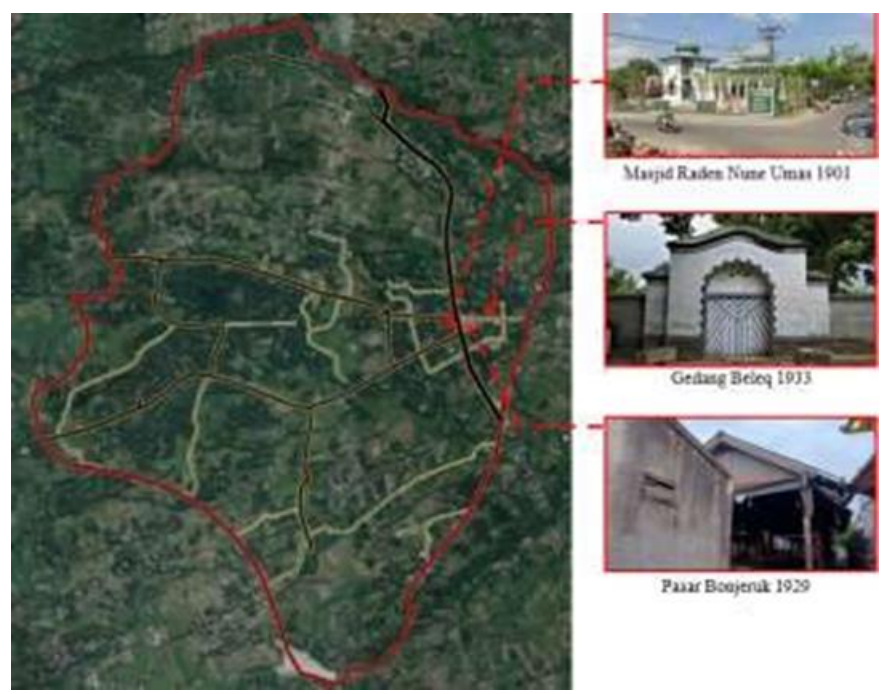

Gambar 7. Objek Sejarah

Terdapat satu jalan primer, yakni Jl. Puyung, yang menghubungkan desa ini ke Kota Mataram dan ke Bandara Praya serta Kuta Mandalika. Ada dua jalan sekunder yang potensial menjadi jalan alternatif ke kawasan desa. Fasilitas yang tersedia di Desa ini adalah Kantor Polsek, SD Negeri, SMP Negeri, Puskesma, Pasar, Masjid, Musholla, dan Makam Umum.

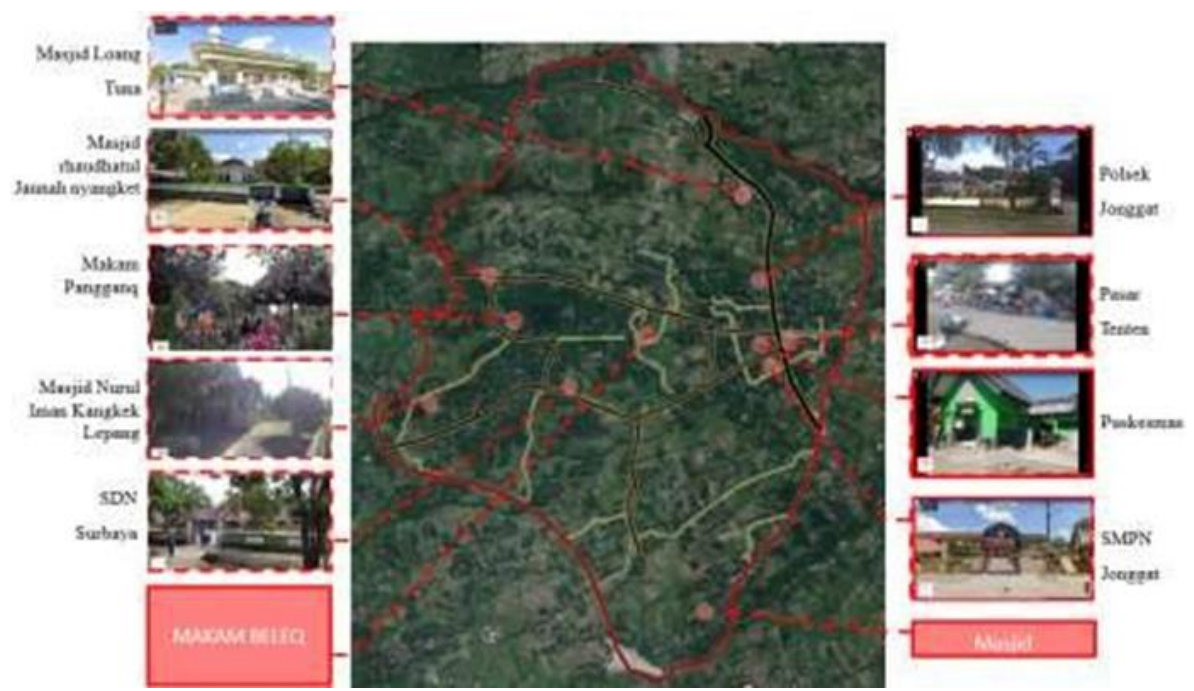

Gambar 8. Infrastruktur

\section{Sistem Visual}

Bangunan Masjid Raden Nune Umas lebih menonjol dari bangunan-bangunan manapun, dan ukurannya yang besar dapat lebih mudah dikenali. Masjid ini sangat potensial dijadikan landmark desa. 


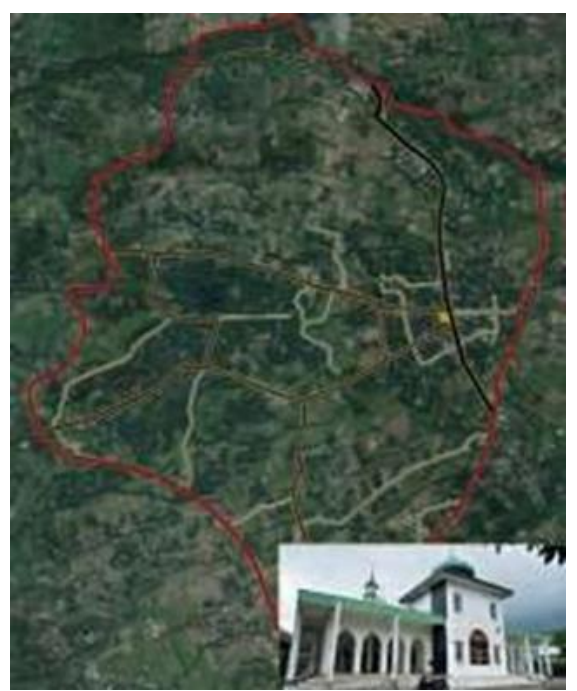

Gambar 9. Landmark

Area yang ramai dan sering menjadi tempat berkumpul oleh warga Desa Bonjeruk terdapat di pusat desa. Tempat ini banyak terdapat kegiatan dan fungsi umum, seperti Masjid, Sekolah, Pasar Lama Tenten, Kantor Desa, dan Puskemas. Wilayah ini perlu divitalkan kembali. Ada beberapa tempat yang perlu ditingkatkan keistimewaannya karena sangat potensial, seperti Pasar Bambu dan Tebing Purba.

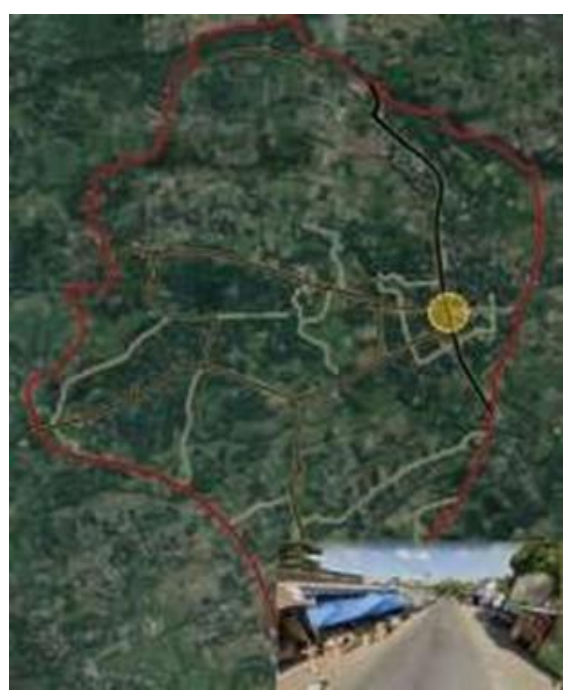

Gambar 10. Tempat Berkumpul dan Spesial

\section{Komposit Pemetaan}

Setelah menganalisis data yang terdiri dari beberapa peta, maka peta-peta tersebut digabunggabung berdasarkan sistemnya dengan cara melakukan layering membentuk komposit degradasi. Hal ini dilakukan, supaya terlihat lokasi mana yang memiliki karakter kuat dan mana yang lemah. 

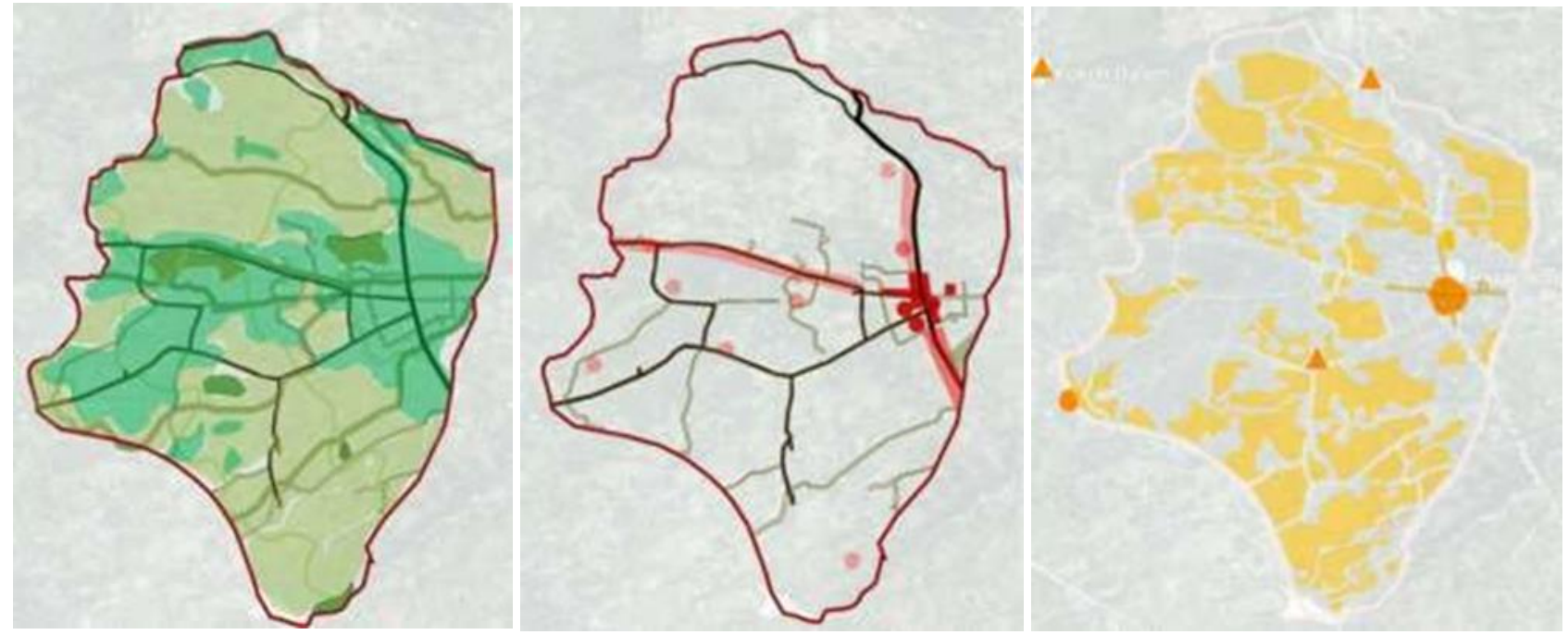

Gambar 11. Komposit Sistem Alamiah, Sistem Budaya, dan Sistem Visual

Seperti yang kita lihat warna yang lebih gelap memiliki kekuatan karakter. Dari ketiga peta tersebut kita gabungkan lagi untuk membentuk sati komposit yang utuh.

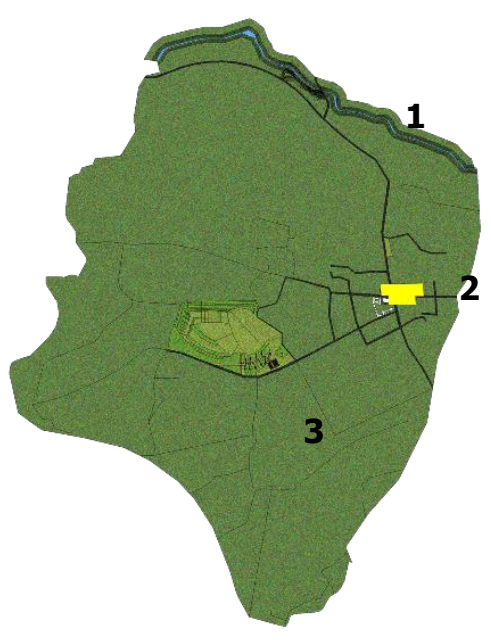

Gambar 12. Komposit Spirit of Place Desa Bon Jeruk

Dari peta komposit tersebut didapat tiga zona yang potensial yang meiliki karakter kuat di Desa Bonjeruk. Ketiga zona ini lalu dikembangkan pada tahap perencanaan konsep berupa masterplan, adalah sebagai berikut:

1. Zona Wisata Alam: Sungai, Air Terjun, Tebing Purba, Camping, dan Permakultur 


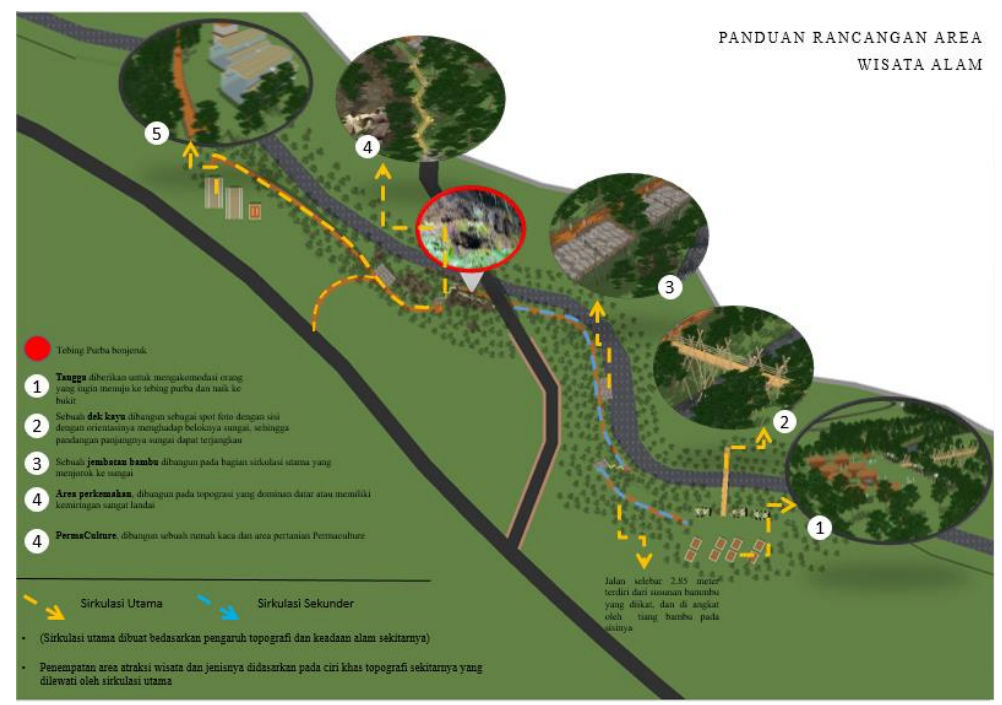

Gambar 13. Rencana Zona Wisata Alam

2. Zona Wisata Sejarah dan Budaya: Masjid, Pasar, Balai, Alun-alun, dan Gedang Beleq

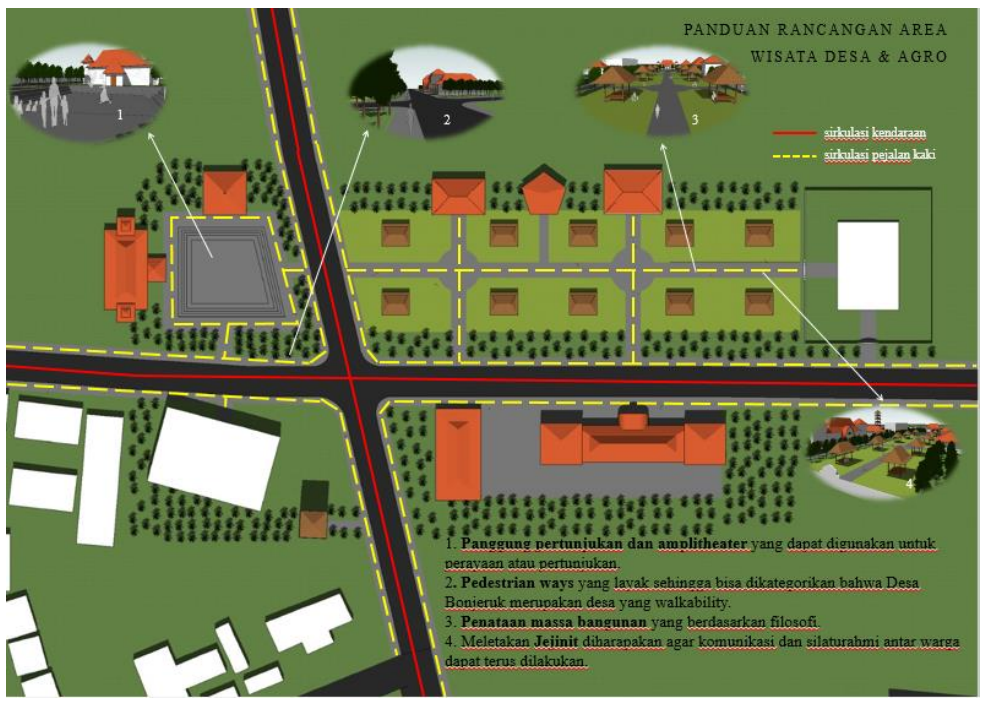

Gambar 14. Rencana Zona Wisata Sejarah dan Budaya

3. Zona Wisata Agro dan Pedesaan: Pasar Bambu, Sawah, dan Homestay

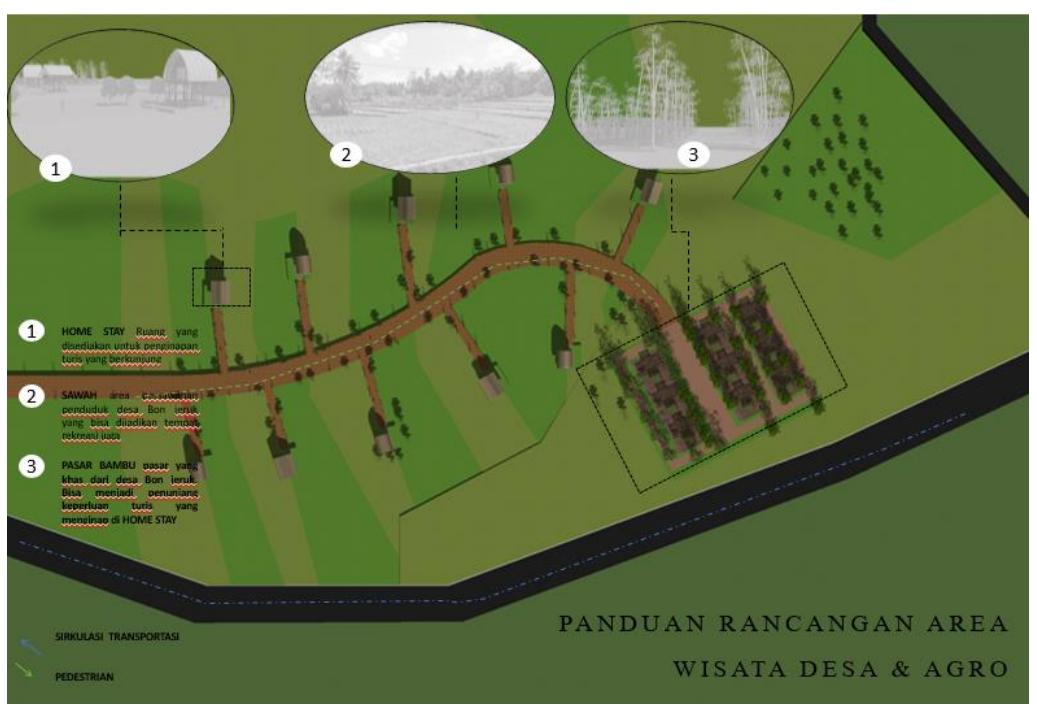




\section{Gambar 15. Rencana Zona Wisata Agro dan Pedesaan}

Bangunan-bangunan baru diarahkan mengikuti gaya Art Deco, percampuran antara gaya kolonial Belanda dan gaya tradisional Lombok. Penataan ruang-ruang luar dan dalam mengikuti pola penataan ruang-ruang permukiman dan bangunan tradisional Lombok (Organisasi Ruang, Sirkulasi Ruang, Hirarki Ruang, dan Orientasi). Material bangunan: Badan Bangunan dari Batu dengan penyelesaian eksterior dengan lempung atau serupa warna lempung dan Atap dari alang-alang alami dengan pengawetan atau sintetis. Material jembatan dan gerbang: bambu alami dengan pengawetan atau bambu sintetis. Gubahan Massa bangunan mengadopsi bangunan tradisional Lombok untuk jenis atapnya dan bangunan kolonial untuk badan bangunannya.

Tabel 1. Rencana Panduan Arsitekturan Bangunan di Desa Bonjeruk

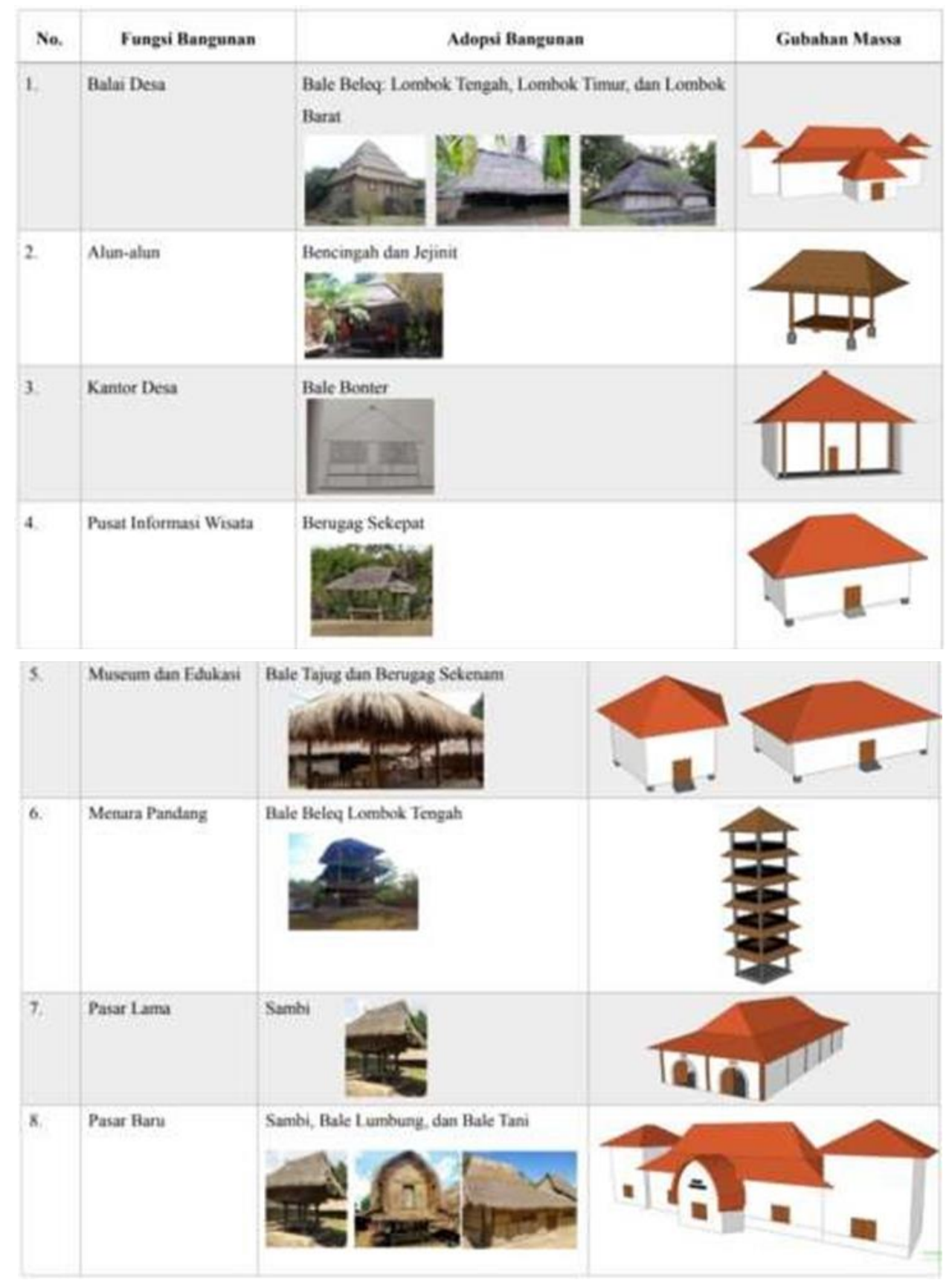




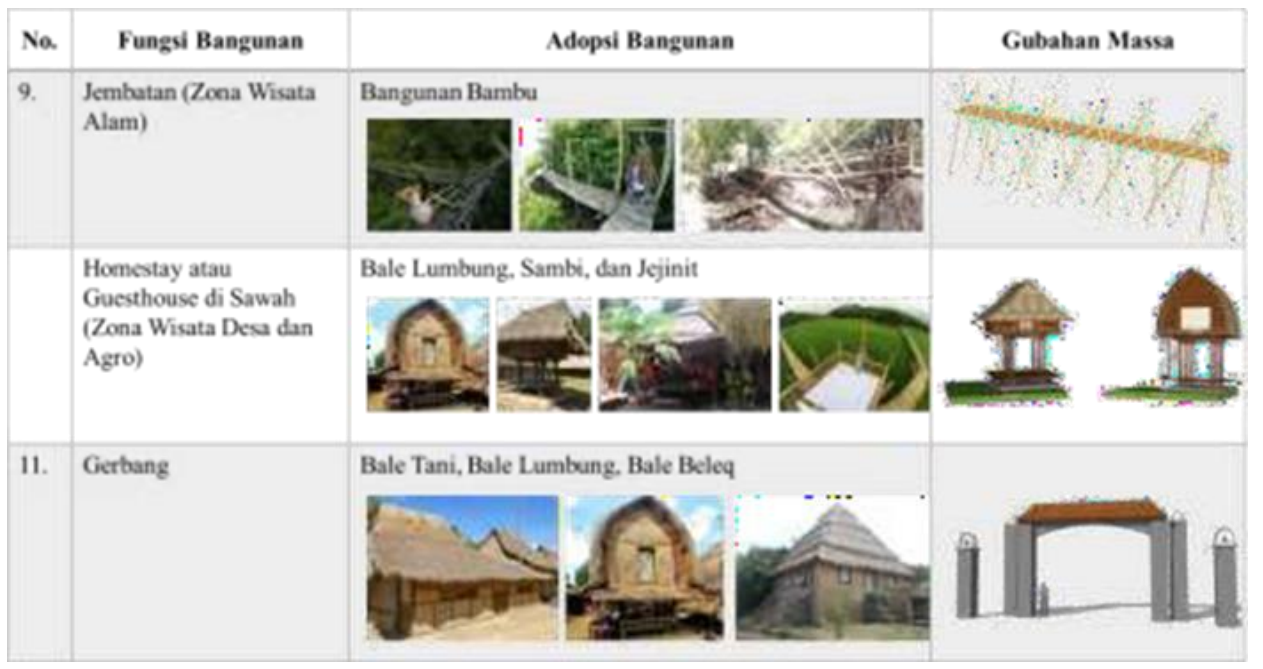

\section{Kesimpulan}

Desa Bonjeruk memiliki potensi besar untuk menjadi desa wisata, selain karena persawahannya yang terbentang luas, alam yang masih sangat terjaga, juga kebudayaan desa yang masih sangat kental. Hal inilah yang sangat meyakinkan bahwa dengan sedikit perencanaan konseptual pada desa ini, maka Desa Bonjeruk dapat lebih memaksimalkan potensi yang sudah ada.

Penggunaan bahan dari alam, juga adaptasi dari bangunan tradisional Lombok dengan bangunan Belanda sengaja digunakan agar terus menghadirkan citra Desa yang kental dengan budaya dan sejarah tanpa merusak alam dan tatanan Desa Bonjeruk. Dengan adanya pengembangan yang menyeluruh pada bagian desa bonjeruk, diharapkan dapat memajukan perekonomian masyarakat sekitar, dan melestarikan adat sekitar.

\section{Daftar Pustaka}

Anjani, Lale Rizka Quratul (2018). Strategi Komunikasi Politik Kekuasaan Dalam Menjaga Eksistensi Keluarga Kerajaan di Desa Bonjeruk Kecamatan Jonggat, Lombok Tengah. Skripsi thesis, Universitas Mercu Buana Yogyakarta. [diakses pada 1 September 2020]. dari eprints.mercubuana- yogya.ac.id/3338/2/BAB\%20I.pdf

Garnham, H. L. (1985). Maintaining The Spirit of Place: A Process for The Preservation of Town Character. Arizona: PDA Publishers Corp.

Khafid. S. (2019). Pelesiran ke Desa Bonjeruk: Sawah, Sejarah, dan Kopi Enak. Tempo.com. [Diakses 13 September 2020] dari https://travel.tempo.co/read/1280876/pelesiran-ke-desabonjeruk-sawah- sejarah-dan-kopi-enak

NTB.GO.ID (2019). WAGUB NTB Resmikan Desa Wisata Bonjeruk. [Diakses

pada september 2020] dari https://lomboktengahkab.go.id/index.php/artikel/berita/wagub-ntbresmikan-desa-wisata-bonjeruk 